\title{
La integración curricular de la Comunicación No Verbal en la Enseñanza Primaria y en la Secundaria: para el enriquecimiento académico y vivencial del alumno
}

Recibido: octubre 2011

\author{
Fernando POYATOS \\ Universidad de New Brunswick, Canadá \\ fpoyatos@telefonica.net
}

Aceptado: marzo 2012

\begin{abstract}
RESUMEN
Se trata de un triple plan para la implementación académica del campo de la Comunicación No Verbal, en una progresiva adaptación de sus diversas áreas, en las enseñanzas Primaria y Secundaria, a fin de sensibilizar a sus alumnos a la realidad cotidiana de su comunicación no verbal con los demás y con su entorno, lo cual enriquecería su desarrollo personal desde una temprana edad. A. En la Enseñanza Primaria, 1, concienciándoles de la comunicación personal basada en la realidad tripartita del discurso (palabras-la voz con que se emiten-los elementos con que simultáneamente se hacen visibles) y de las peculiaridades de las tres modalidades básicas para ellos más comunes: cara a cara, por teléfono, por escrito. En la Enseñanza Primaria, 2, el modelo curricular progresa en su presentación de los diversos signos no verbales y de su comportamiento personal general, además de introducir a los alumnos en la observación de lo no verbal en la literatura y los artes. B. Para la Enseñanza Secundaria se presenta la realidad de su propia adquisición de competencias verbales y no verbales (con características universales, culturales, subculturales y hasta familiares), viendo ya más detalladamente: los distintos fenómenos del paralenguaje, la kinésica (gestos, maneras, posturas, y funciones de los rasgos faciales); los posibles problemas interculturales en su ámbito escolar cada vez más multicultural (siendo necesaria hoy no sólo la 'fluidez comunicativa', sino la 'intercultural'); las dos dimensiones de espacio (proxémica) y tiempo (cronémica) en nuestra vida diaria; el silencio y sus funciones; comunicación no verbal en la literatura (realzando los diversos aspectos del 'acto de lectura') y en tres áreas importantes: pintura, fotografía y publicidad. Con sus numerosos ejemplos y su bibliografía, la estructura y presentación de este modelo ofrecen una sólida base para la elaboración de materiales de enseñanza.
\end{abstract}

Palabras clave: comunicación no verbal, Enseñanza Primaria y Secundaria, currículo

The curricular implementation of nonverbal communication in primary and secondary schools: Towards the students' academic and experiential enrichment

\section{ABSTRACT}

This is an outline of a threefold plan for the curricular implementation of the field of Nonverbal Communication, in a progressive adaptation of its various areas, in primary 
school and secondary school, in order to sensitize pupils to the daily reality of their nonverbal communication with others as well as their environment, which would enrich their personal development from an early age. A. In Primary School, 1, making them conscious of personal communication as being based on the tripartite reality of speech (words-the voice with which they are emitted-the elements that make them simultaneously visible) and the peculiarities of the modalities most basic for them: face-to-face, by phone, in writing. In Primary School, 2, the curricular model progresses in its presentation of the various nonverbal signs and their personal general behavior, besides introducing students to the observation of the nonverbal in literature and the arts. B. For Secondary Teaching, it presents the reality of their own acquisition of verbal and nonverbal skills (with universal, cultural, subcultural and even family characteristics), now dealing in more detail with: the different phenomena of paralanguage, kinesics (gestures, manners, postures, and the functions of facial features); the possible intercultural problems in its growingly multicultural school environment (for which both 'communicational' and 'intercultural' 'fluency' are needed today); the two dimensions of space (proxemics) and time (chronemics) in our daily life; silence and its functions; nonverbal communication in literature (emphasizing the various aspects of the 'reading act') and in three important areas: painting, photography and publicity. With its many examples and its references, the structure and presentation of this model offer solid ground for the preparation of teaching resources.

Key words: nonverbal communication, primary school, secondary school, curriculum

\section{L'intégration curriculaire de la communication non verbale dans l'Éducation Primaire et Secondaire : pour un enrichissement académique et expérientiel des élèves}

\section{RÉSUMÉ}

Il s'agit d'un triple plan pour l'implémentation académique du champ de la Communication Non verbale, dans une adaptation progressive de ses divers domaines, dans l'enseignement Primaire et Secondaire, pour sensibiliser ces élèves à la réalité quotidienne de leur communication non verbale avec les autres et avec leur environnement, ce qui enrichirait leur développement personnel à partir d'un jeune âge. A. Dans l'Enseignement Primaire, 1, les rendant conscients de la communication personnelle basée sur la réalité tripartite du discours (des mots; la voix avec laquelle ils sont émis; les éléments avec lesquels ils deviennent simultanément visibles) et des particularités des trois modalités de base pour eux les plus communes : vis à vis, par téléphone, par écrit. Dans l'Enseignement Primaire, 2, le modèle curriculaire progresse dans la présentation des divers signes non verbaux et du comportement personnel en général, en plus d'introduire les élèves dans l'observation du non verbal dans la littérature et les arts. B. Pour l'Enseignement Secondaire on présente la réalité de leur propre acquisition des compétences verbales et non verbales (avec des caractéristiques universelles, culturelles, sous-culturelles et même familières), avec plus de détail : les phénomènes distincts du paralangage, le kinésique (gestes, manières, postures, et fonctions des traits faciaux); les problèmes interculturels possibles dans leur milieu scolaire de plus en plus multiculturel (aujourd'hui on y a besoin non seulement de "l'aisance communicative », mais de «l'aisance interculturelle »); les deux dimensions dans notre vie 
quotidienne : l'espace (proxémique) et le temps (chronémique); le silence et ses fonctions; la communication non verbale dans la littérature (en remarquant les divers aspects de «l'acte de lecture ») et dans trois domaines importants : la peinture, la photographie et la publicité. Avec ses nombreux exemples et sa bibliographie, la structure et la présentation de ce modèle offrent une base solide pour l'élaboration de matériels d'enseignement.

Mots clef : communication non verbale, Enseignement Primaire et Secondaire, curriculum

Sumario: Introducción: la realidad de la comunicación no verbal en el aula y en la vida del alumno y su planteamiento curricular. I: La comunicación no verbal en la enseñanza primaria, 1. ¿Cómo nos comunicamos? Cara a cara. Hablando por teléfono. Escribiendo. La comunicación no verbal en la enseñanza primaria, 2. ¿Cómo nos comunicamos? Más signos corporales percibidos sensorialmente. Los signos del cuidado personal. Nuestras pertenencias. Nuestro comportamiento en general. La literatura y el arte. II: La comunicación no verbal en la Enseñanza Secundaria. Adquisición de las competencias verbales y no verbales en el desarrollo del discurso como actividad tripartita. Las categorías paralingüísticas. Kinésica, cualidades parakinésicas y rasgos faciales. La kinésica transculturalmente y los problemas interculturales. La proxémica y la cronémica transculturalmente. El silencio y sus funciones. Percepción sensorial directa y sinestésica. La comunicación no verbal en la literatura. La comunicación no verbal en pintura, fotografía y publicidad. Conclusión. Referencias bibliográficas.

\section{INTRODUCCIÓN: LA REALIDAD DE LA COMUNICACIÓN NO VERBAL EN EL AULA Y EN LA VIDA DEL ALUMNO Y SU PLANTEAMIENTO CURRICULAR}

Cronológicamente, mi anterior contribución a Didáctica. Lengua y Literatura, «La formación académica sobre los libros y la lectura a través de los estudios de comunicación no verbal» (Poyatos 2010) ${ }^{1}$, podría haber sido mejor una derivación del presente artículo, puesto que éste trata de ofrecer una serie de sugerencias aplicando a la Enseñanza Primaria y a la Secundaria mis estudios dentro del muy interdisciplinar campo de la Comunicación No Verbal, a fin de sensibilizar a los alumnos de ambos niveles a los muchos aspectos de la comunicación que no sólo podrían descubrir en sus estudios, sino en su vida diaria.

En la Enseñanza Primaria encontramos a niños entre los 6 y los 11 años, y de los 12 a los 16 en la Secundaria. En las dos, pues, nos enfrentamos con edades en las cuales se desarrolla su formación académica, social, moral y espiritual (a menudo con un gran desequilibrio entre estos cuatro aspectos esenciales en su vida). Pues bien, la idea de hacerles sensibles a la realidad de la comunicación no verbal está muy lejos de ser una curiosidad marginal para comentar en el aula todo lo más esporádicamente. De hecho, a nivel universitario, en mis últimos veinte años de docencia impartía tres

${ }^{1}$ De una conferencia en la Facultad de Ciencias de la Educación, mayo 2009. 
cursos diferentes sobre Comunicación no Verbal en los departamentos de Antropología, Sociología y Psicología, por sus muchas e importantes aplicaciones en diversas áreas de enseñanza e investigación en esos tres campos. ${ }^{2}$

Pues bien, la comunicación no verbal está implícita en muchos de los campos de estudio incluidos en los currículos de la Primaria y la Secundaria, ya que constituye una insoslayable realidad inherente a la comunicación entre los seres humanos y a cuanto nos rodea allá donde nos encontremos en nuestra existencia diaria. Aparte de que lo no verbal está presente en el aula misma donde se desarrollan esas disciplinas, tanto en la conducta de profesores y alumnos como en su entorno físico, como estudiábamos en mi curso de Sociología, especialmente interdisciplinar. ${ }^{3}$ Hacer conscientes a los alumnos de esa realidad cotidiana contribuye a enriquecer su desarrollo personal. Efectivamente, desde el momento en que adquirimos cierto control sobre los niños fuera de sus hogares - y eso empieza incluso antes de ser admitidos al nivel primario - podemos beneficiar ese desarrollo ontogénico a través de sus tareas escolares haciéndoles conscientes paulatinamente de sus propias competencias comunicativas más allá de las palabras, incluso sensibilizándolos a deseables 'estilos no verbales' de los que tal vez carezca el entorno familiar de algunos de ellos. De hecho, una vez que empezamos a enseñarles la lengua sistemáticamente, solemos adolecer de cierta miopía, ya que nosotros mismos, para enseñar a esos alumnos, nos estamos comunicando con ellos verbal y no-verbalmente; lo cual significa que debemos ser muy conscientes de que, por añadidura, nuestro propio discurso verbal-no verbal puede muy bien actuar como modelo que ellos, consciente e inconscientemente, puedan adoptar e incorporar al desarrollo de esas competencias comunicativas. Por eso es importante desde el principio que les hagamos conscientes de cómo en su diario vivir están adquiriendo unos repertorios no verbales, complementarios a su expresión verbal, con características, primero, universales, y después nacionales (culturales), regionales (subculturales), domésticas (familiares) y, por supuesto, individuales.

Si no lo hacemos así, estaremos ocultándoles, para empezar, la verdadera realidad de su propia forma de hablar, de su discurso, que es, como mínimo, una realidad tripartita formada por palabras (lenguaje verbal), por el cómo las emiten sobre todo oralmente (paralenguaje) y por el cómo visualmente utilizan sus cara, sus ojos, sus

2 Aunque llevaba ya más de quince años tratando estos temas en publicaciones, en conferencias y en congresos, así como en simposios internacionales que yo mismo organizaba en distintas disciplinas, pero casi siempre interdisciplinarmente.

${ }^{3}$ Con temas como el entorno del aula y los comportamientos en ella, la interacción enfermera-paciente, la publicidad, los interrogatorios policiales, la novela, el teatro, el cine, las entrevistas de trabajo, los buenos modales verbales y no verbales en los diversos niveles sociales, la arquitectura y el urbanismo como entorno de comportamientos, la decoración interior en distintos hogares, y otros. 
manos y hasta todo el cuerpo (kinésica) para decir lo que dicen y hasta cuando no dicen nada, pero quieren hacerse entender. ${ }^{4}$ Por eso hay que ir haciéndoles comprender que esos cambios de su voz se van adaptando perfectamente a lo que dicen y que, aunque no digan nada con palabras, sus gestos, maneras y posturas representan no sólo sus pensamientos e intenciones no verbalizados, sino a menudo lo que también podrían decir hablando.

Lo dicho hasta ahora parece equivaler ya a una primera lección para niños, que no deja por eso de ser una síntesis de lo que podríamos desarrollar más eruditamente. Imaginemos por un momento dos congresos simultáneos con un tabique por medio: uno para niños y otro para sus sesudos profesores. En el nuestro se espera que estemos diciendo las cosas muy seriamente, mientras que en el de ellos les explicamos prácticamente lo mismo, pero de tal modo que nos daría vergüenza hablar así entre nosotros porque, al entenderse todo demasiado fácilmente, muchos ya no se lo tomarían tan en serio.

Por otra parte, probablemente la mayoría de esos niños hayan pensado de algún modo en la comunicación no verbal; y, desde luego, todos la han experimentado, como recordaba san Agustín de su niñez, según nos dice en sus Confesiones, sin referirse a 'lenguaje', 'paralenguaje' y 'kinésica', pero pensando exactamente en eso tres canales de nuestro discurso:

[...] yo mismo, con el entendimiento que Vos, Dios mío, me disteis [...] empecé a fijar en la memoria cuando ellos nombraban alguna cosa; y cuando, al nombrarla, la señalaban con algún movimiento del cuerpo, yo, al verlo, entendía [..] descubríase por los gestos del cuerpo, que son como palabras naturales [...] y se hacen con el rostro, con la mirada y con diversos movimientos de los otros miembros, y con la modulación de la voz [...] y así empecé a usar los mismos signos que los otros.

Una vez planteada esta insoslayable realidad social, se trataría de adaptarse, en términos adecuados, primero, a los distintos niveles del currículo de la Enseñanza Primaria, para que aprendan a apreciar en qué consiste la comunicación y, por supuesto, los conceptos de 'lenguaje', 'lengua' y 'habla' (cada uno en sus dos manifestaciones, verbal y no verbal), es decir, desde lo universal hasta lo nacional y lo regional de su propio 'hablar' (ej., habla andaluza o madrileña). Así, pues, veamos cómo llevar a cabo, en términos prácticos, la gradual incorporación en la Enseñanza Primaria, y luego en la Secundaria, de lo que supone en realidad la observación de uno mismo respecto a: las competencias que constituyen el hablar; la apreciación de cómo los demás utilizan esas competencias; $\mathrm{y}$, a través de medios personales y medios audiovisuales, el análisis comentado de esas realidades comunicativas. Todos los

\footnotetext{
${ }^{4}$ El profesor encontrará, como fuentes para una programación sistemática y progresiva de estas materias: Poyatos 1993, 1994, 2002, 2003, 2004.
} 
temas tratados en la Primaria los ampliaríamos en la Secundaria, pero añadiendo nuevos aspectos y áreas.

\section{I.- LA COMUNICACIÓN NO VERBAL EN LA ENSEÑANZA PRIMARIA, 1}

Intentemos primero, pues, proponer cómo puede incorporarse la enseñanza de la comunicación no verbal en la Enseñanza Primaria, indicando sus dos etapas, pero dejando la distribución del material al criterio de quienes deban decidir el currículo, siempre que esas personas estén suficientemente versadas en el campo de la Comunicación No Verbal. Debemos empezar por ofrecer a los alumnos -por supuesto, modificando nuestro vocabulario según las necesidades- una definición suficientemente realista (y con ejemplos adecuados a cada uno de los dos niveles de enseñanza), de lo que es comunicación no verbal, que (interpolando aquí algunos ejemplos comprensibles para los niños) normalmente he definido como:

las emisiones de signos activos (una palabra, un grito, un estornudo, un gesto) o pasivos (mi ropa, mi peinado), constituyan o no comportamiento (hablar lo es, pero no la decoración interior de mi casa), a través de los sistemas corporales no léxicos (mi tono de voz, mis gestos, mi sonrojo), objetuales (las cosas que llevo a clase) y ambientales (la lluvia, la música) contenidos en una cultura (por la 'manera de ser' de su país, los niños japoneses dejan de ser tocados por sus familiares a partir de los cinco o seis años y tradicionalmente la gente se saluda con una inclinación), sólo en uno de esos sistemas (juntando y separando dos veces los dedos de una mano para significar 'atestado') o en mutua coestructuración de dos o más (haciendo el gesto y diciéndolo a la vez con palabras).

Que los alumnos se den cuenta de que esta definición se basa en el hecho de que tanto nosotros, seres socializantes, como el entorno estamos emitiendo constantemente signos no verbales, de los cuales muy a menudo son más conscientes los demás que nosotros mismos, con consecuencias positivas o negativas en nuestra interacción con ellos.

En la Enseñanza Primaria - donde tenemos a alumnos de 6 a 9 años -, a la vez que debe fomentarse en el aula la observación de los comportamientos más conspicuos en el uso de los sistemas de signos no verbales por parte de ellos y de los profesores, se trata de plantear y definir ciertos principios teóricos y prácticos para sensibilizar a esos niños al hecho de que no nos comunicamos solamente con palabras, es decir, a la presencia de los tipos de signos no verbales que mejor puedan observar ellos y comprender. Esto puede hacerse siguiendo (con un lenguaje a veces aún más sencillo que el que utilizo deliberadamente en estas páginas) el esquema de la Fig. 1, "Didáctica de la comunicación no verbal en la Enseñanza Primaria". 5

\footnotetext{
${ }^{5}$ En la Bibliografía (que limito casi sólo a publicaciones en español), además de mis tres volúmenes de 1994 (bastante más al día los de 2002), pueden encontrarse materiales para su adaptación didáctica.
} 


\begin{tabular}{|c|c|c|c|}
\hline \multicolumn{4}{|c|}{ Nos comunicamos } \\
\hline \multirow{4}{*}{$\begin{array}{l}\text { ENSEÑANZA } \\
\text { PRIMARIA } \\
1^{\circ} \text { a } 4^{\circ} \\
(6 \text { a } 9 \text { años })\end{array}$} & Hablando & \multirow{2}{*}{\multicolumn{2}{|c|}{$\begin{array}{l}\text { Con palabras que podemos escribir } \\
\text { Con cambios de voz que no podemos escribir }\end{array}$}} \\
\hline & cara & & \\
\hline & a cara & \multicolumn{2}{|c|}{ Con gestos a la vez o en lugar de palabras } \\
\hline & $\begin{array}{l}\text { Hablando } \\
\text { por teléfono }\end{array}$ & \multicolumn{2}{|c|}{$\begin{array}{l}\text { Con palabras, cambios de voz y casi los } \\
\text { mismos gestos, pero sin verlos }\end{array}$} \\
\hline \multirow{14}{*}{$\begin{array}{l}\text { ENSEÑANZA } \\
\text { PRIMARIA } \\
5^{\circ} \text { a } 6^{\circ} \\
(10 \text { A } 11 \\
\text { años) }\end{array}$} & Escribiendo & \multicolumn{2}{|c|}{$\begin{array}{l}\text { Palabras como las que decimos (pero sin } \\
\text { cambiar de voz) y signos de puntuación } \\
\text { para leerlas bien nosotros solos o en voz alta }\end{array}$} \\
\hline \multicolumn{4}{|c|}{ Nos comunicamos con: } \\
\hline & Lenguaje & Lenguaje & Los tres componentes de \\
\hline & verbal y & Paralenguaje & nuestro discurso, que sigue \\
\hline & no verbal & Kinésica & desarrollándose a esta edad \\
\hline & Gestos & \multicolumn{2}{|c|}{ /Sí/, /No/, /Es así de alta/, /Ven aquí/, /Vete/, /¡Adiós!/ } \\
\hline & Maneras & \multicolumn{2}{|c|}{$\begin{array}{l}\text { Cómo andamos, damos la mano, comemos, bebemos, } \\
\text { escribimos }\end{array}$} \\
\hline & Posturas & \multicolumn{2}{|c|}{$\begin{array}{l}\text { De pie, sentados, cruzados de brazos o piernas, de rodillas, } \\
\text { en cuclillas }\end{array}$} \\
\hline & $\begin{array}{l}\text { Signos que } \\
\text { vemos u olemos }\end{array}$ & \multicolumn{2}{|c|}{$\begin{array}{l}\text { Lágrimas, sonrojo, palidez, bronceado, sudor, } \\
\text { mal aliento, perfume, colonia }\end{array}$} \\
\hline & $\begin{array}{l}\text { Cuidado personal } \\
\text { Ropa y calzado }\end{array}$ & \multicolumn{2}{|c|}{$\begin{array}{l}\text { Pelo, ropa planchada o no, limpia o sucia } \\
\text { zapatos sucios/limpios, piercings, tatuajes }\end{array}$} \\
\hline & $\begin{array}{l}\text { Objetos } \\
\text { personales }\end{array}$ & \multicolumn{2}{|c|}{$\begin{array}{l}\text { Libros, juguetes, materiales de trabajo (usándolos, } \\
\text { conservándolos bien o mal) }\end{array}$} \\
\hline & & $\begin{array}{l}\text { En el } \\
\text { aula }\end{array}$ & $\begin{array}{l}\text { Atento, distraído, mal sentado, } \\
\text { hablando al profesor, a la clase }\end{array}$ \\
\hline & $\begin{array}{l}\text { Nuestro } \\
\text { comportamiento }\end{array}$ & $\begin{array}{l}\text { Dentro } \\
\text { de casa }\end{array}$ & $\begin{array}{l}\text { Nuestras cosas ordenadas o no } \\
\text { Nuestra voz y gesto con los demás }\end{array}$ \\
\hline & & $\begin{array}{l}\text { Fuera de } \\
\text { casa }\end{array}$ & $\begin{array}{l}\text { En la calle, de visita, de viaje, } \\
\text { en la iglesia, en la playa }\end{array}$ \\
\hline & \multicolumn{2}{|c|}{$\begin{array}{l}\text { Comunicación no verbal } \\
\text { en literatura y arte }\end{array}$} & $\begin{array}{l}\text { Descripción en textos literarios } \\
\text { Representación en pintura figurativa }\end{array}$ \\
\hline
\end{tabular}

Fig. 1 Didáctica de la Comunicación no Verbal en la Enseñanza Primaria: 


\section{¿CÓMO NOS COMUNICAMOS? ${ }^{6}$}

De una manera lógica y natural - y evitando absolutamente en este primer nivel primario toda terminología especializada (que no debería aparecer hasta la enseñanza secundaria)-, se trata de comentarles e ilustrarles, con ejemplos, los tres modos básicos que tienen de comunicarse a diario: hablándose cara a cara, hablándose por teléfono, y escribiéndose, con lo cual llegarán a diferenciar claramente lo verbal y lo no verbal.

\section{Cara a cara}

Nos comunicamos sobre todo hablándonos unos a otros en clase, en casa, jugando. Pero, ¿cómo lo hacemos?, ¿cómo nos hablamos?, y ¿qué utilizamos para hablarnos y entender lo que nos decimos?

1. Ante todo, nos hablamos con las palabras que hemos ido aprendiendo en casa, en la calle y en clase. Son palabras que también hemos aprendido a escribir, aunque unas con más dificultad que otras. Pero ya entre esas palabras encontramos que, así como la mayoría no parecen tener nada que ver con lo que significan (casa, niña, toro), otras, en cambio, imitan sonidos (ej., 'El agua gorgotea por la acequia', 'El cordero está balando', 'El toro hace '¡Muu!') o movimientos (ej., 'Y ipataplúm!, se cayó', 'Y le dió: ¡zas!'). Esto en cuanto a las palabras, que ellos aún están aprendiendo, es decir, el vocabulario de su lenguaje verbal.

2. Pero cuando nos hablamos unos a otros, reconocemos que, dependiendo de quién hable, de lo que diga, del cómo lo diga, y de a quién se lo diga, y las circunstancias de cada uno en ese momento, aunque se digan esas mismas palabras, suenan diferentes. ¿Por qué? Porque, incluso sin que nos demos cuenta, consciente o inconscientemente, cambiamos la voz según cómo queramos decir una o más palabras (ej., en broma, con mala intención, con mucho respeto).

A. Claro que cada uno tenemos una voz distinta, lo que hace incluso que la de un profesor o un compañero o compañera de clase nos guste más o menos. Efectivamente, si los alumnos oyen que dos profesores que conocen están conversando fuera del aula, ellos los diferencian perfectamente aunque no entiendan lo que se dicen, porque lo que los diferencia es el timbre de su voz ('más como de hombre, aun siendo mujer', 'como si fuera mayor'), la primera característica en el hablar que nos hace a cada uno diferente. Además, subimos el tono: para avisarle a alguien si se va a caer: " Cuidado, que te caes!”; si estamos alegres: “¡Papá, mamá, me han dado un sobresaliente!”; si algo nos gusta mucho: “¡Estupendo!”; y así se tiende a hablar también a los niños pequeñitos: “iQué bonita es ella!"; pero bajamos el tono si estamos tristes, desanimados o cansados:

6 Este esquema puede desarrollarse visualmente en forma de gran cartel añadiendo algunas viñetas a continuación de algunos de los ejemplos. 
"Me han suspendido", "Estoy rendido". Por eso un profesor debe tener una entonación melodiosa, porque si es monótona, es decir, sin apenas cambiar el tono, puede ser aburridísimo. Alargamos las vocales (y hasta podemos imitarlo al escribir si las repetimos, por ejemplo: dudando ("Puees...no lo sé"), llamando de lejos (“¡Pee-pii-too!”), admirados (“Oooh!”) sintiéndonos a gusto (“iAaaah, qué bien se está aquí!"); o las acortamos (pero eso podemos hacerlo al escribir, por ejemplo: como en un tono de enfado (" $\mathrm{NNi}$ hablar!'), o hablando secamente

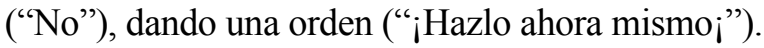

B. Pero, además, cuando hablamos, aparte de que cada uno tenemos una voz diferente, podemos también cambiarla de muchísimas maneras (aunque algunas causas pueden hacerla permanente) según la intención con que queramos decir algo, por ejemplo: susurramos o bisbiseamos para decirnos algo en clase sin que nos oiga el profesor o hablando al oído de alguien (pero a veces no tenemos más remedio que hablar así si nos hemos quedado roncos de tanto gritar en la feria o por habernos resfriado); murmuramos cuando leemos o cantamos muy bajito para nosotros mismos; algunas de las mujeres que venden en los mercadillos nos llaman con voz chillona, y los que gritan siempre mucho o fuman mucho o beben mucho, pueden tener una voz áspera que se parece a la de los cuervos; la voz nos sale trémula si hablamos muy emocionados o con miedo de decir en casa que nos han suspendido, y hasta balbuciente o entrecortada cuando, por ejemplo, estamos hablando y sollozando a la vez; algunos malos de las películas hablan con voz hueca o cavernosa (como si hablaran dentro de una caverna) para meter miedo; muchos niños mimados les piden a sus padres lloriqueando que les compren algo. Por supuesto, no debemos hablar con la boca llena, porque es de mala educación y, hablando así, mascullamos las palabras porque no podemos articularlas bien.

C. También hablamos a veces riéndonos, o reímos sin hablar a la vez, y la risa puede sonar muy diferente según por qué riamos: porque nos hacen cosquillas, porque la profesora pone una cara muy chistosa, porque estamos nerviosos, porque nos han aprobado cuando no lo esperábamos, cuando un pistolero de una película del Oeste desafía a otro, porque de pronto sentimos alivio después de pasar mucho miedo con algo. Lo mismo pasa con el llanto, es decir, que sonamos muy diferentes según el motivo por el que lloremos o hablemos llorando a la vez: porque se nos ha muerto alguien muy querido, o le recordamos, porque hemos hecho algo malo y nos arrepentimos, o de rabia porque nos han pegado (aunque no nos duela). Y la tos, el hipo, el estornudo, el bostezo o el eructo hacen también que la voz nos salga diferente $\mathrm{y}$, además, nos considerarán mejor o peor educados según sepamos o no controlar esas reacciones delante de los demás.

D. Por último, lo mismo que aprendemos nuevas palabras de nuestra lengua, también desde pequeños nos vamos formando una especie de vocabulario con muchos sonidos independientes de las palabras, que son realmente como palabras (y algunos hasta los encontramos en el diccionario: ‘ZZas!', ‘Pum!') y emitimos con diferentes significados ('Puf’, ‘'Guau-guau!', 'Miau', ‘'Aj!'). El problema es 
que, así como algunos podemos escribirlos -y debemos intentar hacerlo, siempre que el que lo lea lo entienda-, la mayoría no, aunque los usamos con tanta frecuencia: un soplo para apagar una vela, un gruñido, una tos, un carraspeo para indicar que viene el profesor, un suspiro, un estornudo, un leve chasquido de lengua porque algo nos da pena, imitando el gorgoteo del agua o el crujir de algo, el sonido de la bofetada, el de sorber la sopa o el de llamar a la puerta con los nudillos. Pero donde sí podemos encontrar muchos de estos sonidos es en los cómics o tebeos, a pesar de que contienen muchas imitaciones de sonidos que los que hablan inglés sí pueden escribir, pero no nosotros; y por eso, si no sabemos inglés, podemos pronunciarlos mal. Aparte de que bastantes de esos son (pero no lo sabemos) verdaderas palabras inglesas que imitan ciertos sonidos y que no tenemos en español: 'iSlam!', portazo; 'Squeak', chirrido; 'Flop', por ejemplo, dejarse uno caer en un asiento o en la cama; 'Twang', el sonido de algo vibrante; 'Swish-swish', el de algo cortando el aire, como dos espadas batiéndose.

Pues bien, hasta aquí les hemos sensibilizado a las cuatro categorías que comprende el paralenguaje, aunque sin darles aún la terminología ("cualidades primarias", "calificadores" o tipos de voz, "diferenciadores", "alternantes"). En cuanto a los "alternantes", sería eficaz que los niños, como tarea de casa, reconocieran algunos de los que ellos mismos utilizan a diario (por ejemplo, jugando), que identificaran los que aparecen en sus cómics y tebeos, y que elaboraran pequeños inventarios de unos y otros para reconocer su propia capacidad de expresión como hablantes.

Finalmente, para agudizar su sensibilidad al entorno, pidamos a esos niños que nos cuenten sus propias experiencias cuando ciertos sonidos no humanos, por sus características, nos suenan como voces cuando los 'oímos', y hasta los 'escuchamos' (ique no es lo mismo!): el rechinar de una puerta, el murmullo de un arroyo, el sonido del viento, el de algunos materiales resquebrajándose.

3. Hasta aquí les hemos hecho conscientes de los distintas actividades sonoras de su hablar. Pero, volviendo al niño Agustín, a quien debemos citarles de nuevo - «con el rostro, con la mirada y con diversos movimientos de los otros miembros»-, ellos mismos, como él, nos dirán que cuando hablamos también nos entendemos con las manos, con los ojos, sacándole la lengua a alguien, saludando de lejos, unas veces hablando a la vez y otras sin decir palabra, pero entendiéndonos. Efectivamente, y todo eso constituye lo que es en realidad la tercera parte de su discurso, lo que la literatura divulgadora y menos científica suele llamar 'lenguaje del cuerpo', que nosotros conocemos (aunque no les mencionemos el término por ahora) como kinésica: gestos, maneras y posturas. Precisamente por tratarse de lo que todo el mundo asocia con la comunicación no verbal -'los gestos', sin más -, no debemos poner demasiado énfasis en ello, sino solamente, confirmar su presencia constante en nuestra comunicación desde el momento que despertamos cada día y comenzamos a relacionarlos con los demás. Todo lo más, tal vez, hagamos en clase alguna 
demostración, por ejemplo, haciéndoles notar sus propios gestos en cualquier momento y, si hay alumnos nacidos en otras culturas, o lo son sus padres, tal vez, suscitar en ellos algunos gestos que puedan diferir de los nuestros, lo cual podremos buscar mejor en las demostraciones con informantes de otras culturas, comentadas más tarde al tratar de la Educación Secundaria.

\section{Hablando por teléfono}

Para hacer a los alumnos conscientes de la importancia de la comunicación no verbal, pidámosles que se observen a sí mismos y a los demás cuando están hablando por teléfono. Así se darán cuenta de que, aunque no vemos a nuestro interlocutor, no sólo usamos las mismas modificaciones de la voz y las mismas emisiones independientes que si nos estuviéramos viendo, sino que no dejamos por eso de acompañar lo que decimos, con palabras y esos cambios de la voz, de todo tipo de gestos de toda la cara, de los ojos y de las manos. Y esto -es importante que los alumnos lo entiendan- ocurre así porque, sencillamente, lo que se llama 'hablar' se compone de sonidos y movimientos: se oye y se ve; y, si conocemos a la otra persona, nos la imaginamos hablando, riéndose y moviéndose al decir lo que nos dice. Por ejemplo, me hizo gracia en Japón ver a una niña que hablaba por teléfono con otra y, al despedirse, le hacía la misma inclinación desde la cintura que si la tuviera delante.

\section{Escribiendo: la puntuación, comunicación no verbal}

Sin embargo (como podemos indicarles más concretamente más adelante), la mayoría de esas palabras, si las escribimos, aparte de unos pocos cambios de la voz que podemos indicar con unos pocos signos de puntuación (como se verá después), no podremos nunca representarlas tal como nosotros podemos hacerlas sonar cuando las decimos con muy diferentes intenciones.

Los alumnos deben ser conscientes de cómo todas las palabras que decimos son susceptibles de representarse por escrito, pero que de todos esos cambios de la voz que utilizamos para hablarnos, apenas podemos escribir ninguno para, al leer esas palabras, saber exactamente cómo imaginarlas. Lo único que podemos representar es lo que es una pregunta, porque ponemos el signo de interrogación antes, [i], y después, [?]; también, si queremos indicar que lo que escribimos se dice en voz alta, ponemos antes de la palabra o frase [i] y [!] al final, y hasta lo duplicamos, [ii !!] o triplicamos, [iii !!!]. ${ }^{7}$ Pero esos son los únicos signos que tenemos si queremos representar el decirle a un compañero al oído: “¡Cuidado, que viene el profe!”. ¡Con lo bien que nos vendría tener un signo de puntuación para representar el hablar muy

\footnotetext{
${ }^{7}$ Puede que algún niño que sepa inglés, francés, catalán o árabe, nos diga que si escribe una pregunta sólo lo pone al final, [?], y que hace lo mismo con la admiración, [!], con lo cual verán que el español castellano escrito es en ambos casos el más claro de todos los idiomas.
} 
bajito o cuchichear! Pero nadie se preocupó de inventarlo. ${ }^{8}$ Y, aparte de estos dos signos, escribimos a veces tres puntos seguidos, [...], para significar que alargamos la última palabra, como al decir "Bueno..., yo...no sé qué decirte".

Sin embargo, ya en este nivel de la Enseñanza Primaria se debe sensibilizar a los niños al hecho maravilloso de la oralización (Poyatos 2010: 292), es decir, de cómo las palabras escritas cobran vida con su lectura, tanto mental como oral, incluso bisbiseándolas para sí, y de cómo en esa lectura les van añadiendo esos cambios de la voz que han empezado a estudiar ahora, según ellos imaginan esas palabras habladas al leerlas, especialmente leyendo un cuento o un tebeo. Así confirmarán una vez más la mutua inherencia de los elementos verbales y los no verbales en su propia lengua. Por esta razón conviene que tratemos de corregirles ciertas tendencias, muy corrientes a esas edades, por ejemplo, cuando les oímos leer de una manera irrealista las frases marcadas por los signos de interrogación, que incluso muchos mayores (ej., leyendo en la iglesia) hacen sonar infantilmente. Que, al hacerles leer en clase, se les haga ver esa artificialidad: “¿A que no haces esa misma pregunta así cuando estás hablando?”.

\section{LA COMUNICACIÓN NO VERBAL EN LA ENSEÑANZA PRIMARIA, 2}

Veamos ahora cómo en los dos últimos años de la Primaria podemos ampliar un poco más concretamente los conceptos ya introducidos, para que los alumnos, además de ciertas definiciones básicas, adquieran una visión más amplia de la comunicación no verbal y puedan observarla en ellos mismos, en sus interacciones diarias y en la televisión y el cine.

\section{¿CÓMO NOS COMUNICAMOS?}

Aquellas tres formas, simultáneas o alternas, de transmitirnos mensajes unos a otros -es decir, por medio de palabras, de los cambios de la voz al decirlas (más esas casi-palabras como ' $i J e ! '$, 'Bis-bis-bis', 'Clic') y de los movimientos de la cara y el cuerpo- son las que se reconocen como los tres componentes de nuestro hablar, del discurso, que, como hemos visto, es en realidad un conjunto de tres actividades que desarrollamos conjuntamente desde la infancia: lenguaje verbal-paralenguajekinésica.

En cuanto a la kinésica, movimientos y posiciones, tanto para observar nuestra conducta y la de los demás como para hablar de ellos o preparar algún trabajo de clase, debemos diferenciar entre:

- gestos, acompañando las palabras o por sí solos: con la mano para indicar la estatura de una persona o un perro (¡que, según las culturas, no es igual!), para llamar a alguien, para hacerle burla, para que se calle, para decir adiós en una estación, etc;

- maneras, acompañando las palabras o por sí solas: no sólo la manera de caminar, de cruzarnos de brazos o piernas, de escribir (ej., torciendo la cabeza y

\footnotetext{
${ }^{8}$ Un resumen del desarrollo de la puntuación, en Poyatos 2002, Vol. III, pp. 126-129.
} 
sacando la punta de la lengua), sino lo que llamamos modales sociales, buenos o malos, en nuestras relaciones con los demás: cómo damos la mano, un abrazo o un beso, cómo comemos ("Esa niña no sabe comer"), cómo andamos, sobre todo las mujeres, según la ropa que llevemos, etc.

- posturas (y también aquí hablamos de buenos o malos modales): el estar sentados, de pie, en cuclillas, recostados en un sofá o acostados en la cama o en la playa.

\section{Más signos corporales percibidos sensorialmente}

Pero no sólo nos comunicamos con la voz, los movimientos y las posturas estáticas, sino también con otros signos producidos por nuestro cuerpo, que tocamos, vemos u olemos: táctilmente sentimos la suavidad de una cara (signo dérmico), visualmente percibimos signos químicos, como las lágrimas y el sudor (pero el sudor también olfativamente) y otros dérmicos, como el sonrojo (algunos alumnos se sonrojan fácilmente), la palidez y el bronceado (que puede indicar vacaciones en la playa, trabajo en el campo, etc.); pero también hay otros que creamos nosotros y que los demás perciben, como son los signos químicos artificiales del perfume o la colonia.

\section{Los signos del cuidado personal}

Además de los signos naturales ya vistos hay otros que no son verbales ni corporales - pero casi, e igual de personales-, por los que la gente nos juzga positiva o negativamente; y no sólo a nosotros, sino tal vez a nuestra familia, a nuestros padres (“¡Cómo lo lleva siempre de arregladito!”, “¡Hay que ver, cómo me lleva al pobre!”). Se trata de todo aquello que delata el cuidado que tenemos o no tenemos de nuestra propia persona ("Fulanito va siempre muy aseado"), lo cual empieza en la misma aula: la ropa (limpia, más bien 'dudosa', sucia, arrugada o bien planchada), el calzado limpio o sucio.

\section{Nuestras pertenencias}

También esas cosas comunican muy claramente sin palabras, o sea, no verbalmente, tanto en nuestra casa como en el aula. Por ejemplo, cómo conservamos nuestros cuadernos, nuestros libros de texto o los que nos regalan (Poyatos 2010: 293), nuestros juguetes, una bicicleta, etc.

\section{Nuestro comportamiento en general}

Por último, para completar una visión general de la comunicación no verbal, debemos hacer a los alumnos conscientes de todo aquello que, sobre todo visualmente, llamamos su comportamiento, lo cual, como es fácil de comprender, refleja nuestra manera de pensar y de sentir sobre nuestras propias relaciones con aquellos que nos rodean diariamente y con quienes tenemos que relacionarnos en cualquier lugar. En clase podemos estar atentos o distraídos, sentados como corresponde a los buenos modales o no, hablando respetuosamente o no al profesor (o sea, con palabras, paralenguaje y kinésica apropiados). En nuestra casa, según las palabras, voz y gesto con que hablemos a los demás (amables, ásperos, de mala gana 
cuando nos mandan hacer algo, siempre reflejando una buena disposición). Y fuera de casa, nuestra manera verbal-no verbal de conducirnos es muy importante en la calle, estando de visita, con personas que conocemos durante un viaje, en la iglesia (sin hablar ni distraernos), en la playa, en el cine y en otros sitios públicos.

\section{LA LITERATURA Y EL ARTE}

Finalmente, dos áreas llenas de posibilidades para la observación y estudio de lo no verbal, que se ampliarán en la Enseñanza Secundaria, son:

- las obras literarias que leemos en esta segunda etapa de la Enseñanza Primaria, de las cuales disfrutarán mucho más si se fijan en cómo los escritores nos describen y evocan muchos elementos no verbales, por ejemplo, leyendo Platero y yo, de Juan Ramón Jiménez: «Cuando, entre un olor a naranjas, se oye el hierro alegre y fresco de la noria, Platero rebuzna y retoza alegremente», o en el Quijote: «Digo que fue tanto [el enojo de don Quijote], que, con voz atropellada y tartamuda lengua, lanzando vivo fuego por los ojos, dijo:/ - ¡Oh bellaco villano [...] ¡»;

- las obras artísticas que ven los alumnos, bien en los libros de texto, cuando el profesor se las enseña o cuando los lleva a visitar un museo. Sobre todo en cuadros de historia y en la llamada pintura de género y costumbrista, que representan de una manera realista acontecimientos, entornos y personas que nos dejan ver sus gestos. Mostrémosles, por ejemplo, cuadros que puedan serles familiares, pero en los que ahora apreciarán aspectos no verbales en los que antes ni habrían pensado (ej., $E l$ testamento de Isabel la Católica, del decimonónico Eduardo Rosales; Los fusilamientos de La Moncloa, de Goya; Y aún dicen que el pescado es caro, de Joaquín Sorolla).

Si distribuimos el material hasta aquí resumido de forma sencilla, como corresponde a los seis años de la Enseñanza Primaria -ilustrándolo a menudo con ejemplos vivos de su propia experiencia, tanto la del profesor como la de sus alumnos-, se habrán sensibilizado indudablemente a la presencia de la comunicación no verbal en muchos aspectos de su vida diaria en los que antes ni habían pensado. Esto proporcionará un gran aliciente a su currículo académico, ya que estos temas están relacionados con otras materias de su programa, bien se decidiera distribuir el material en las disciplinas más apropiadas para ello o, lo que probablemente sea menos factible, presentarlo todo junto en una breve asignatura sobre comunicación no verbal.

\section{II.- LA COMUNICACIÓN NO VERBAL EN LA ENSEÑANZA SECUNDARIA}

En la Enseñanza Secundaria, es decir, entre los 12 y los 16 años, encontramos una vertiente en la que los alumnos acceden con más profundidad al estudio de la lengua, la literatura, la historia, el arte y la sociedad y la cultura en general. Como en la Primaria, los niveles ya algo más elevados de la comunicación no verbal pueden incorporarse fácilmente dentro de esas materias en los dos últimos años, mientras que una asignatura por separado las abarcaría más sistemáticamente. En cualquier caso, resumámoslas aquí también siguiendo la Fig. 2, "Didáctica de la comunicación no verbal en la Enseñanza Secundaria”. 


\title{
Adquisición de las competencias verbales y no verbales
}

\author{
Cualidades básicas: timbre, tono, etc. \\ Calificadores: tipos de voz \\ Diferenciadores: reír, llorar, \\ Paralenguaje gritar, suspirar, estornudar, \\ hipar, eructar, bostezar \\ Alternantes: 'Mm', 'Sss', 'Glu-glu' \\ gruñido, gemido, soplo, sorbo \\ Representación en cómics
}

Gestos: manos, dedos, ojos, boca, hombros

Kinésica Maneras: modo de moverse y modales sociales Posturas: cuerpo, brazos, piernas, manos, ojos

ENSEÑANZA Parakinésica Intensidad, presión, velocidad SECUNDARIA

$1^{\circ}$ a $4^{\circ}$

(12 a 16 años)

Rasgos faciales: permanentes, dinámicos

La kinésica transculturalmente (informantes)

Proxémica y cronémica transculturalmente (informantes)

El silencio y Expresar por sí mismo, realzar sonidos, sus funciones realzar acción anterior

Percepción sensorial Visual, auditiva, táctil, directa y sinestésica cinestésica, olfativa, gustativa

Comunicación Interacción personal con los libros no verbal en El 'acto de lectura'

literatura Elementos no verbales en novela y poesía

Pintura: figurativa (representación) y no figurativa (evocación) Fotografía: el álbum familiar, manipulación periodística

Fig. 2 Didáctica de la Comunicación no Verbal en la Enseñanza Secundaria 


\section{Adquisición de las competencias verbales y no verbales en el desarrollo del discurso como actividad tripartita}

Lo que a los alumnos de Primaria se les indicó ya, sin muchos detalles, acerca de la naturaleza triple de nuestro hablar, debe presentarse ahora algo más detalladamente, empezando por comentar el desarrollo de las competencias verbales y no verbales e indicándoles que esos compañeros extranjeros que tal vez tengan en clase 'lo tienen más difícil', ya que, como ya no son niños, traen consigo sus propias competencias lingüístico-culturales que, por tanto, interfieren con las que deben aprender en aquellos puntos en que difieran ambos sistemas lingüísticos.

1. A estos alumnos de Secundaria se les hará ver que, como hablantes, estuvieron desde muy niños aprendiendo progresivamente la fonética de su idioma, en la que cometían errores de articulación que iban superando por corrección paterna e imitación (¡aludamos de nuevo a los recuerdos de la niñez de San Agustín!); que iban aprendiendo y corrigiendo los cambios morfológicos (ej., 'me sabó' por 'me supo'); que iban adquiriendo igualmente la necesaria sensibilidad para la organización sintáctica de su discurso; y que, simultáneamente, iban siempre aumentando su vocabulario. Todo eso es lo verbal de su lengua.

2. A la vez, hagámosles conscientes de haber ido adquiriendo su paralenguaje, es decir, diferentes modificaciones significativas básicas de la voz (ej., entonación monótona para denotar desinterés o describir alguna acontecimiento aburridísimo, elocuentes ascensos y descensos del tono de voz, etc.), tipos de voz voluntarios que de niños no sabían utilizar (ej., voz hueca haciéndose los importantes o autoritarios, voz muy nasal para fingir ñoñería, susurrando para denotar sigilo, laringalización de tono grave expresando sarcasmo), formas de risa que tampoco usaban de niños (ej., riendo con ironía, concepto antes desconocido), así como un creciente número de, por ejemplo, espiraciones nasales (ej., de impaciencia), chasquidos linguales (ej., un "Tz, pobre chico" de conmiseración), expresiones de asco o sorpresa que no usaban antes, etc.

3. Y al lenguaje verbal y al paralenguaje iban añadiendo, como parte normal del desarrollo de su hablar o independientemente, no sólo la kinésica debida a ciertos hábitos motores innatos universales, sino cuanto iban aprendiendo aisladamente o en combinación con los sonidos, además de las cualidades parakinésicas (que vamos a ver aquí). Pero, claro, todavía sin las sutilezas del 'vocabulario kinésico' que poseen ahora - el cual sigue aumentando hasta ser totalmente de adulto en sus gestos, maneras y posturas-, y sin dominar ni interpretar bien aún todas sus posibilidades funcionales al observar a los demás, porque, incluso ahora, aún siguen desarrollando su triple capacidad de emisión, recepción e interpretación.

4. A este triple complejo de su discurso el alumno de Secundaria va asociando diversas actitudes y situaciones proxémicas al valorar cada vez más correctamente las distancias interpersonales, las muchas funciones del contacto físico interpersonal, e incluso las diferencias interculturales, que ahora pueden observar en compañeros de otros países, y tal vez viajando al extranjero. Y, naturalmente, el concepto y 
significado sociales de los otros sistemas corporales, por ejemplo: reacciones químicas, como el llanto (a su edad ya más controlado según las circunstancias); reacciones dérmicas, especialmente el sonrojo, las situaciones que lo suscitan ahora (en comparación con su niñez) y las conductas que lo acompañan. Finalmente, también han venido desarrollando desde la niñez la valoración y uso del tiempo en las relaciones sociales, es decir, la cronémica (el sentido de la puntualidad, de la tardanza, de lo que una visita debe durar según las circunstancias, etc.).

\section{Las categorías paralingüísticas}

Volvemos ahora al paralenguaje. Como ya vimos bastantes ejemplos, demos ahora sus nombres a sus cuatro categorías, ilustrándolas de nuevo:

- las cualidades primarias eran las características básicas de cada hablante (timbre, tono, intensidad o volumen de voz, etc.): «-Y el señor que esperaba a la puerta, ¿era tu padre?/ Su voz tomó un tono sombrío» (Delibes, La sombra del ciprés es alargada);

- los calificadores son, además de otros muchos, aquellos tipos de voz que identificamos ya en la Primaria y que utilizamos según la intención con que digamos lo que decimos (ej., las mismas palabras susurrándolas suavemente, susurrándolas con ira, articulándolas tensamente), aunque algunos puedan ser causados por ciertos defectos (ej., ronquera): «don Quijote] llamó al ventero, y, con voz muy reposada y grave, le dijo:[...] el ventero le respondió con el mismo sosiego» (Cervantes, Don Quijote);

- los diferenciadores realmente diferencias ciertos estados fisiológicos y psicológicos o emocionales (ej., la risa, el llanto, el jadeo, el grito, reflejos como el hipo, la tos, el estornudo, el eructo), pero nos han enseñado a controlar algunos de ellos, como el estornudo, el bostezo y el eructo (este último considerado incluso obligado en culturas árabes como elogio de la comida): «Ten cuenta, Sancho, de no mascar a dos carrillos, ni de erutar delante de nadie» (Cervantes, Don Quijote);

- los alternantes, todas esas casi-palabras la mayoría de las cuales ya vimos que no podemos escribir, pero que las usamos con tanta facilidad y significado como las palabras mismas: 'Mmm,' 'Sss', 'Glu-glu', ‘Plom!', gruñidos, gemidos, resoplidos, ronquidos, una aspiración para pedir la palabra, soplos, sorbos, 'Y pasó, ¡Ffffp!, como una flecha', etc. Una vez más, los alumnos pueden identificar aquellos alternantes siempre que no se trate de verdaderas palabras inglesas (como encontramos a menudo) que, si hubieran traducido, tampoco tendrían sentido, como SLAM (portazo), KNOCK-KNOCK! (llamando a la puerta): «De cara... psh; soy insignificante» (Galdós, Miau), «Sirvió Manuel la sopa, la tomaron todos los huéspedes, sorbiéndola con un desagradable resoplido» (Baroja, La busca).

\section{Kinésica, cualidades parakinésicas y rasgos faciales}

En primer lugar, conviene repasar las formas y funciones de gestos, maneras y posturas (especialmente los gestos), pero en Secundaria hablando ya de dos cosas 
más: de sus cualidades parakinésicas y de los rasgos faciales, por su íntima relación mutua.

Las cualidades parakinésicas (lo mismo que hablábamos del paralenguaje con relación al lenguaje verbal) pueden hasta cambiar el significado de un mismo gesto (ej., un lentísimo o rápido ‘ ¡No!') o de una manera (dando la mano con efusiva presión). Los alumnos deben practicar estas calificadores en la clase y diferenciarlos claramente. Estas cualidades que califican nuestras conductas kinésicas -de las cuales el profesor puede a veces incluso proporcionarles ejemplos tomados de nuestra literatura, son: intensidad (tensión muscular): «Don Andrés saco una pitillera de oro. Tomó delicadamente un cigarrillo» (Caballero Bonald, Dos días de setiembre); presión: «Ana, al darle la mano [a Mesía] tuvo miedo de que él se atreviera a apretarla un poco» (Alas, La Regenta); campo (el espacio abarcado): «[Andrés, reconociéndole] arremetió a don Quijote y, abrazándole por las piernas, comenzó a llorar» (Cervantes, Don Quijote); velocidad: «El muchacho del mono azul mahón [...] se volvió de espaldas, girando con una pausada impertinencia» (Caballero Bonald, Dos días de setiembre); duración: «[bebiendo de las botas] meneando las cabezas a un lado y a otro [...] se estuvieron un buen rato» (Cervantes, Don Quijote).

En cuanto a los rasgos faciales, los alumnos -que pueden recoger fotos de periódicos y revistas y comentarlas, ofreciendo sus propias opiniones sobre ellasdeben reconocer que la cara es el vehículo primordial de nuestras interacciones y que hablamos a través de nuestra fisonomía facial, diferente en cada persona (según variaciones culturales, ontogénicas, temperamentales e interactivas). Es importante que reconozcan la importancia de sus propios rasgos faciales y de los de los demás. Se trata de considerar sus funciones en esas interacciones personales de cada día, tanto en los primeros encuentros - puesto que las primeras impresiones cuentan mucho- como incluso cuando mandamos nuestro retrato a alguien, por ejemplo, como parte de un currículo al solicitar una beca o un puesto de trabajo. En nuestra 'cara hablante' hay cuatro tipos de rasgos:

- permanentes (dimensiones craneales y características de los ojos, nariz, labios, mejillas, barbilla, dientes, etc.), como ilustra nuestro famoso Arcipreste de Hita, Juan Ruiz: «Busca muger de talla, de cabeça pequeña [...] las çejas apartadas, luengas, altas, en peña [...] Ojos grandes, somneros [...] de luengas pestañas [...] las orejas pequeñas, delgadas [...] el cuello alto [...] La nariz afilada, los dientes menudillos,/ eguales, e bien blancos, un poco apartadillos;/ las enzivas bermejas [...] los labros de la boca bermejos, angostillos./ La su boca pequeña» (Ruiz, Libro de buen amor);

- cambiantes, debido a la edad, el sufrimiento, el tipo de trabajo, etc.: «un cambio tal [...] Los ojos los tenía apagados; el pelo se le había puesto totalmente gris; su rostro estaba ajado; su figura había menguado [...]» (Collins, The Moonstone);

- dinámicos, es decir, cuando esos rasgos permanentes y estáticos se activan al hablar, de tal modo que unos rasgos que consideramos atractivos, no lo son tanto al hablar, mientras que los que nos parecen incluso feos pueden cobrar un encanto especial al fundirse con la voz y los gestos de la manos, lo cual hasta influye en 
nuestras interacciones: «Y hablando [Jacinta], sus atractivos eran mayores que cuando estaba callada, a causa de la movilidad de su rostro y de la expresión variadísima que sabía poner en él» (Galdós, Fortunata y Jacinta);

- artificiales (labios pintados, cintas del pelo, gafas, pendientes, etc.), pero que pueden influir en los otros rasgos y tener ellos mismos importantes consecuencias interactivas, como lo vuelve a ilustrar el arcipreste Juan Ruiz: «Ojos grandes, somneros, pintados, reluzientes (Ruiz, Libro de buen amor). Incluso podemos mencionar como artificiales esos piercings, que, lo mismo que los tatuajes, no todos se sienten llamados a ostentar, y que, indudablemente, pueden influir en los encuentros. Los alumnos pueden hacer sobre ambos un breve cuestionario por escrito o de palabra (incluso en la clase). Y siempre podría ser constructivo comentar cómo 'esas cosas', que se convierten en verdaderos rasgos personales que asociamos con la cara, son percibidos junto con el lenguaje y pueden suscitar los más diversos juicios personales, a menudo negativos.

\section{La kinésica transculturalmente y los problemas interculturales}

A la edad de los alumnos de Secundaria es importantísimo hacerse conscientes de la diversidad cultural en el ámbito tan importante de la kinésica, lo cual contribuirá a evitar el posible etnocentrismo de algunos (o, peor, la xenofobia) y a crear lazos más estrechos con miembros de otras culturas, que pueden ser compañeros de estudios -aparte de que hoy día los españoles viajan por todo el mundo--, puesto que el estar bien sensibilizados a los comportamientos no verbales ayuda siempre a valorar los estilos de otros grupos étnicos y culturales y a comportarse mejor como emisores y como receptores.

La Enseñanza Secundaria ofrece una gran oportunidad para mostrarles esa diversidad a lo vivo, para lo cual nada mejor que proporcionarles un grupo de informantes nativos de diferentes culturas -algunos de los cuales pueden encontrarse entre ellos- para que, al menos una vez, hagan una demostración delante de ellos. Tal como yo lo he practicado durante veinte años a nivel universitario en dos de mis cursos de comunicación no verbal en dos departamentos diferentes (Antropología y Sociología), los alumnos reciben cada uno una hoja (con espacio para hacer anotaciones) con una lista de unos veinte conceptos. Esta actividad, siempre bien recibida por los alumnos, les ilustra kinésicamente cómo algunos gestos (sobre todo), maneras y posturas son iguales entre ellos, o difieren en algo, o tienen un significado ofensivo en algunas culturas, o son totalmente distintos en forma y significado e inexistentes en alguna de ellas (ej., no existe en Ghana el beso, hasta el punto de decirnos un informante: "Tal vez lo hagan los de la clase alta en privado"; ni hay un gesto para 'suicidio' en Malasia porque "es ilegal suicidarse" (como nos dijo el informante malayo sorprendido de la pregunta), o para 'atestado' en inglés. He aquí dos listas susceptibles de modificaciones:

A. 1. Sí/No. 2. Hambre/Comer. 3. Sed/Beber. 4. Muy rico, delicioso. 5. Loco. 6. 12-3-4-5-6-7-8-9-10. 7. Estatura de persona/animal. 8. Perdóname. 9. Ven aquí. 10. 
Vete. 11. ¡Hola! 12. Saludo a distancia (¡Adiós!). 13. ¡Silencio! 14. Saludo afectuoso. 15. Gesto de autoestop. 16. Dinero. 17. Frustración. 18. Mal olor. 19. Gesto reprobatorio. 20. Gesto típico de su cultura.

B. 1. Yo/A mí. 2. ¡Qué calor! 3. Tengo frío. 4. Tengo hambre. 5. Está atestado. 6. Calla/¡Silencio! 7. ¿Qué hora es? 8. Repugnancia. 9. ¡Se acabó! 10. Burla. 11. Se ha suicidado. 12. Señalando a alguien o algo. 13. ¡Tengo una idea! 14. Cigarrillo/fumar. 15. Hace muchísimo tiempo. 16. Dando/recibiendo una cosa. 17. Mujer atractiva. 18. Llamando a un gato/perro. 19. Rechazando. 20. Un gesto típico de su cultura.

\section{La proxémica y la cronémica transculturalmente}

Otros dos aspectos propios de toda cultura, que entran de lleno en los estudios de Comunicación No Verbal, es el de las dos dimensiones en que operamos a diario: espacio y tiempo, los cuales han dado lugar a dos campos de estudio: la proxémica y la cronémica.

La proxémica es nuestra conceptualización, estructuración y utilización de los espacios que mantenemos, o nos separan, de los demás y los que nos rodean en nuestro entorno. Aquí sólo nos interesan, entre sus diversas ramificaciones, las distancias que observamos en nuestra interacción con los demás, incluyendo también el contacto físico. Los alumnos necesitan pensar sólo en tres distancias primordiales: la distancia pública, a través de la cual se tiende a hablar en voz más alta, incluso a gritar, y también a gesticular más, en la calle, en un estadio, etc.; la distancia social, que mantenemos moviéndonos en una feria, en aeropuertos, estaciones y salas de espera o dentro de una gran tienda o supermercado (donde el español en Inglaterra o Norteamérica, deberá excusarse con un 'Excuse me;' o 'Sorry!' si llega a rozar apenas a otra persona o acercarse a ella 'íntimamente', como verá que hace ella); la distancia personal es la que ya puede mostrar marcadas diferencias interculturales, ya que lo que el anglosajón medio considera 'personal', puesto que nos podemos tocar alargando el brazo, es sólo 'social' para nosotros los de países alrededor de todo el Mediterráneo o los latinoamericanos; y lo que ellos consideran distancia intima, es decir, llegando al contacto físico por estar más cerca que a distancia personal, para nosotros puede ser simplemente personal, sin considerarla precisamente íntima. ${ }^{9}$ Por eso resultaría muy instructivo comentar estas diferentes actitudes proxémicas con los mismos informantes que invitamos para demostrar su kinésica. Como se ve, la proxémica está directamente relacionada con el uso lingüístico, incluso con las diferencias entre hablas regionales. Por eso en Andalucía occidental vemos cómo

\footnotetext{
${ }^{9}$ Un compañero de cuarto estadounidense que tuve de estudiante se sintió ofendido cuando, subiendo a un tranvía, otro le ponía la mano en la espalda, como hacíamos todos para conseguir entrar.
} 
muchos hombres, al saludarse afectuosamente, se den o no la mano antes, se tocan o palmean mutuamente en el costado.

En cuanto a la cronémica (término que tuve que acuñar como chronemics en los últimos años 60), se trata de cómo conceptualizamos y utilizamos el tiempo como elemento biopsicológico y cultural que caracteriza nuestros comportamientos y actitudes, y que afecta no sólo a la lengua (ej., alargamiento o acortamiento silábico, ritmo rápido o lento) y a la kinésica (i.e., duración de un gesto o postura), sino a las relaciones sociales (ej., lo que deben durar nuestras visitas, el concepto de 'puntualidad', 'urgencia', 'mañana', 'dentro de un rato', 'enseguida', 'luego', etc.).

Como vemos, tanto en cronémica como en proxémica, todos necesitamos conocer las características de cada cultura, nunca dando por sentado que serán las mismas que en nuestro propio país. Así aprenderemos, cada vez más con mayor sensibilidad, que necesitamos poseer un grado adecuado de fluidez intercultural -sin olvidar, por supuesto, que, por ejemplo, un abrazo que salga del corazón, puede romper positivamente ciertas barreras culturales-, sobre lo cual nuestros alumnos también podrán aprender comparativamente de los informantes invitados.

\section{El silencio y sus funciones}

Si los diversos aspectos de la comunicación no verbal no se incluyen en una sola asignatura (antes sugerida), concretamente en la enseñanza de la lengua, no deben dejarse de considerar los silencios que alternan con las palabras o las sustituyen. Siempre se han estudiado ciertos silencios del discurso - las llamadas junturas internas (dentro de una palabra), externas (entre palabras) y terminales (al final de una oración)-, y algunos silencios actitudinales, puesto que se deben a características de personalidad, cultura y contexto situacional. Pero raramente se ha estudiado el silencio como elemento interactivo, no prestando atención al hecho de que cuando el discurso es interrumpido por una 'pausa', al menos una de las otras dos actividades concurrentes, paralenguaje o kinésica, pueden aún llenar esa aparente laguna (nunca tal laguna semióticamente, puesto que siempre hay signos presentes). Incluso las que suelen considerarse como 'pausas vacías' pueden contener paralenguaje (ej., una desdeñosa espiración narial, un clic aspirado de 'petición de turno' cuando se desea tomar la palabra en una conversación) o kinésica (ej., una sonrisa, un gesto de llamada), o ambos; $y$, a veces, actividades proxémicas, dérmicas, térmicas o químicas susceptibles de transmitir ciertos mensajes tan eficazmente o más que las palabras. Mencionemos sólo tres funciones esenciales de los silencios con relación a las palabras:

- significando por sí mismos por la ausencia misma de palabras que serían de esperar, como cuando alguien no responde a nuestro saludo o pregunta (bien por no querer hacerlo verbalmente o kinésicamente o porque no nos ha oído) o cuando queremos evitar decir algo;

- como portador de la actividad precedente, muy importante porque las palabras ('¡Mentira!', 'Te quiero’) se prolongan y amplifican más intensamente en nuestra 
mente si a ellas sigue una pausa, más eficazmente que si seguimos hablando: «Hubo un silencio total, más profundo en contraste con el escándalo anterior» (Quiroga, Viento del norte); por otra parte, debemos hacer estos breves silencios cuando, por ejemplo, leemos un cuento a niños, en lugar de continuar leyendo sin darles tiempo para asimilar lo que acabamos de leerles e imaginar la escena (ej., que el lobo se ha tragado a la abuela de Caperucita).

- el silencio mismo realzado por ciertos sonidos, por ejemplo, el tic-tac de un reloj, o la lluvia golpeando suavemente la ventana, mientras estamos en íntima conversación con alguien; o como ocurre con el reloj y la pluma en este ejemplo de Wells, intensificado por la posible presencia del Hombre Invisible: «los únicos sonidos en la habitación eran el tic-tac del reloj y la suave estridencia de su cálamo, con prisa [la del Dr. Kemp, inquieto] (Wells, The Invisible Man).

\section{Percepción sensorial directa y sinestésica}

En la Fig. 1 se han indicado algunos signos no verbales, mencionados en el nivel primario, de percepción táctil (ej., un cutis áspero o suave), visual (ej., lágrimas, sonrojo, bronceado, sudor), olfativa (ej., ese sudor, el mal aliento, lociones y perfumes). Cada uno de ellos puede operar en nuestras interacciones combinados con el discurso o por sí solos, incluso transmitiéndonos los mensajes más eficazmente que las mismas palabras. A nivel de la Enseñanza Secundaria conviene volver al tema de la percepción sensorial para mencionar dos cosas muy importantes:

- el sentido llamado cinestesia, íntimamente relacionado con la percepción táctil, que opera a través de músculos, tendones, nervios y articulaciones y nos comunica la posición del cuerpo y sus miembros en el espacio y con relación a todo aquello con lo que entramos en contacto (ej., en un apretón de manos, a la vez que nos saludamos verbalmente, yendo por una escalera, guardando el equilibrio en un autobús urbano junto a los demás);

- el importantísimo fenómeno de la sinestesia: la sensación fisiológica en una parte del cuerpo que no es la estimulada; o dicho de otro modo, el proceso psicológico en virtud del cual un tipo de estímulo sensorial produce una sensación subjetiva secundaria que pertenece a otro sentido. En realidad, creemos oler a café simplemente viendo una cafetera, pues oímos, tocamos, olemos y gustamos 'con los ojos', y podemos imaginar (tal vez equivocadamente, pero no por eso con menos consecuencias interactivas y junto con el lenguaje verbal-no verbal) la consistencia de otro cuerpo por el sonido de sus pasos o por la percepción cinestésica de sus movimientos y peso a través de un asiento compartido mientras nos habla; la suavidad de voz y gestos de la modelo que anuncia un tejido de esa característica nos deja sentirlo con el oído y la vista, no al tacto; o, a la inversa, los rasgos faciales, el vestido, maneras y posturas de la persona que aún no oímos nos sugieren (a veces equivocadamente) ese tipo de voz. Por eso la sinestesia funciona con gran eficacia en las interacciones cotidianas con la gente y con el entorno y, por ejemplo, a través de las técnicas persuasivas de la publicidad. 


\section{La comunicación no verbal en la literatura}

Hasta aquí los alumnos han visto cómo la lengua -mejor dicho, su hablar: lenguaje verbal-paralenguaje-kinésica-, junto con los silencios interactivos, funciona en estrecha relación no sólo con los distintos modos de percibir con nuestros sentidos en todos los aspectos de nuestra vida social, desde el aula y en los recreos hasta cualquier lugar público y el mismo hogar, sino con nuestras actitudes espaciales (proxémica) y temporales (cronémica). También es necesario que en este panorama de la comunicación no verbal muy general, pero suficientemente instructivo, se suscite al menos su interés hacia los aspectos no verbales de los textos literarios que ya están conociendo como lectores. Con ello se enriquecerá esa experiencia lectora al enseñarles a valorar (más allá del estilo, la técnica, etc., en su significado tradicional) la presencia explícita e implícita, en narrativa, teatro y poesía, del paralenguaje, la kinésica y las demás modalidades comunicativas, tanto las no verbales personales (comportamentales o no, conscientes o no, voluntarias o no) como las del entorno y, en general, la experiencia total de lo que podemos y debemos llamar, de manera bien legítima, el acto de lectura. ${ }^{10}$ No olvidemos que se ha hablado mucho del 'acto del discurso', pero no sin limitaciones de percepción si pensamos, como mínimo, en la realidad de la estructura lenguaje verbal-paralenguaje-kinésica.

Para ello, y puesto que su contacto con la literatura supone, esperemos, el acceso directo a ella por los libros, tratemos de aumentar su sensibilidad hacia ellos, es decir, su interacción con el libro antes, durante y después de su lectura; lo que equivale, no lo olvidemos, a competir con los actuales aspectos más negativos y nefastos de los últimos medios audiovisuales. Que el profesor les muestre diversos tipos de libros y ediciones $-\mathrm{o}$ que los alumnos los traigan de la biblioteca de sus padres o abuelospara que reconozcan y valoren la percepción visual, táctil, cinestésica y olfativa de los libros, la diferencia entre distintas ediciones, el valor de las ilustraciones, etc.

Las circunstancias personales del acto de lectura, empezando por el entorno inmediato, puesto que puede condicionar nuestra lectura consciente o inconscientemente: una biblioteca pública, un parque, una cafetería, en un avión, tren o autobús, junto al acogedor fuego de una chimenea, con una tormenta rugiendo fuera, pasando frío, o con mala luz, o cómodamente metidos en la cama. Pocos alumnos habrá que no recuerden la experiencia de su acto de lectura en algunas de estas y otras circunstancias, pero es importante agudizar su sensibilidad (en estos tiempos de la informática) haciéndoles pensar en ello.

En segundo lugar, independientemente de su grado de sensibilidad, debe hacérseles conscientes de la presencia de lo no verbal en un texto narrativo o poético, no sólo más explícitamente por las descripciones y comentarios omniscientes del

\footnotetext{
${ }^{10}$ El tema de los libros y la lectura lo he tratado extensamente en Poyatos 2008, y más en resumen en Poyatos 2005). Sobre los libros, véase también Poyatos 2010.
} 
autor, sino por las asociaciones que ellos mismos establecerán como lectores, ampliando así el alcance de ese texto literario más allá también de lo previsto por su creador: intercambios verbales escritos, descripciones y transcripciones paralingüísticas, descripciones kinésicas y proxémicas, descripción o evocación de otros signos interpersonales y del entorno que se han visto ya, o de sonidos del entorno, algunos de los cuales no hayan conocido los alumnos, bien por pertenecer a generaciones pasadas o por ser propios de otras culturas .

De este conocimiento más íntimo de los textos literarios se deriva de una manera natural el que los alumnos se eduquen como lectores y el que sepan disfrutar de lo que leen a niveles antes desconocidos para ellos. Lo cual es importante precisamente en estos tiempos en que los medios audiovisuales e informáticos están mermando tan alarmantemente la población lectora del mundo entero y haciéndoles desdeñar los conocimientos literarios, al menos desde que se abandonan los medios académicos

\section{La comunicación no verbal en pintura, fotografía y publicidad}

Así como en la Primaria los alumnos pueden empezar a reconocer la presencia de lo que en la pintura se nos comunica no verbalmente, en el nivel secundario se les puede mostrar ya más cuadros figurativos, incluyendo entre ellos aquellos en los cuales, de una manera realista, nos imaginamos a los personajes, por la situación representada, hablando con palabras y paralenguaje y gesticulando y adoptando posturas. La pintura de género española, como la de cualquier otra cultura, se presta muy adecuadamente a este tipo de análisis, pues en ella vemos escenas típicas de costumbres y de la vida diaria, las cuales, además de sugerir la presencia del discurso hablado, muestra no sólo elementos estrechamente vinculados a las conductas kinésicas, como el vestido (manera de andar, de estar sentados o de pie, incluso de gesticular), sino muchas características 'no verbales' de los distintos entornos de interiores y exteriores. Aquí, para no limitarnos a la pintura española, se les puede mostrar escenas típicas de otras culturas, en las que encontramos diversos detalles no verbales personales y del entorno, por ejemplo: la magnífica escena Boda campesina, del flamenco Pieter Brueghel el Viejo; las minuciosamente detallistas y satíricas representaciones dieciochescas del inglés William Hogarth, como su serie Marriage a la Mode, o escenas del realismo ruso de últimos del siglo XIX y primera parte del XX, como No le esperaban, de Ilia Riepin.

En cuanto a la fotografía, algo tan popular hoy con la proliferación de las cámaras digitales, el hablar de ella como arte y en sus niveles menos superficiales enriquecería la sensibilidad de los alumnos hacia sus aspectos no verbales: los rasgos faciales, ya mencionados, tan íntimamente relacionados con la lengua; la gesticulación, sugerida en tantas fotos; la reconstrucción del discurso vivo, reflejado en fotos de personas conocidas. Un material ideal para comentar estos y otros aspectos no verbales pueden ser, en primer lugar, las fotos asignadas a los alumnos como tarea escolar y su estudio subsiguiente en clase. Pero especialmente revelador resultan sus mismos álbumes familiares, a menudo de varias generaciones, donde podrán identificar diversas 
características y circunstancias personales y del entorno, incluyendo el familiar y su evolución a través de los años. Tengamos en cuenta que nuestras fotos representan trozos de nuestras vidas, como lo representan las fotografias de revistas y periódicos, muchas de las cuales evocan los repertorios verbales y no verbales de 'famosos' y 'famosas' (no siempre llegados a esa categoría por razones encomiables).

\section{CONCLUSIÓN}

Espero que estas breves sugerencias para la aplicación de los estudios de Comunicación No Verbal a la didáctica de la Enseñanza Primaria y de la Secundaria - lo cual requeriría un tratamiento más extenso y se prestaría perfectamente, como mínimo, a una utilísima tesis doctoral - hayan aportado al menos una perspectiva útil en ambos niveles. Por otra parte, se habrá visto que los distintos temas pueden distribuirse muy adecuadamente entre las asignaturas de lengua y las de literatura, puesto que todos ellos están directamente relacionados con esos dos campos, que a su vez se enriquecerán al ampliar sus propios intereses. Con ello, además, se añade al currículo un atractivo que los alumnos apreciarían, sin duda alguna, por su carácter práctico.

\section{REFERENCIAS BIBLIOGRÁFICAS}

AGUSTÍN, San (397-400). Confesiones. Madrid: Editorial Apostolado de la Prensa, 1964.

POYATOS, Fernando (1994). La comunicación no verbal, Vol.I: Cultura, lenguaje y conversación; Vol. II: Paralenguaje, kinésica e interacción; Vol III: Nuevas perspectivas en novela y teatro y en su traducción. Madrid: Istmo.

POYATOS, Fernando (1998). «El paralenguaje en el Quijote: inventario completo y bases para su estudio». Signa: Revista de la Asociación Española de Semiótica 7, 293-318.

POYATOS, Fernando (1999). «La kinésica en el Quijote: inventario completo y bases para su estudio». Signa: Revista de la Asociación Española de Semiótica 8, 281-326.

POYATOS, Fernando (2002). Nonverbal Communication Across Disciplines, Vol. I: Culture, Communication, Interaction, Language; Vol. II: Paralanguage, Kinesics, Silence, Personal and Environmental Interaction, Vol. III: Narrative Literature, Theater, Film, Translation. Amsterdam/ Filadelfia: John Benjamins.

POYATOS, Fernando (2003). «Los comportamientos no verbales como contexto y entorno del discurso oral». Oralia: Análisis del discurso oral 6, 283-307.

POYATOS, Fernando (2004). «Los elementos no verbales en los textos literarios: oralidad inherente y presencia explícita e implícita». Oralia 7, 119-148.

POYATOS, Fernando (2004). «Nuevas perspectivas lingüísticas en comunicación no verbal». En Lluis Payrató (ed.), Les fronteres del llenguatge: lingüística $i$ comunicació no verbal. 57-91. Barcelona: Universidad de Barcelona. 
POYATOS, Fernando (2006). «Enfoque integral del habla andaluza y su entorno a través de los elementos verbales y no verbales de sus textos». Oralia, 9, 277-302.

POYATOS, Fernando (2005). «La realidad de la aventura humana ante la palabra escrita: interacción y recreación en el acto de lectura». Desde la Orilla de la Literatura Infantil y Juvenil. III Foro de la Literatura Infantil y Juvenil. 3855.Sevilla: Universidad de Sevilla.

POYATOS, Fernando (2008). «Leyendo a Juan Ramón Jiménez a la luz de los estudios de comunicación no verbal». En M. Victoria Galloso (ed.), Estudios en torno a la lengua y la literatura en Andalucía. 193-218. Granada: Editorial GEU.

POYATOS, Fernando (2008). Textual Translation and Live Translation: The Total Experience of Nonverbal Communication in Literature, Theater and Cinema. Amterdam/Filadelfia: John Benjamins.

POYATOS, Fernando (2010). «La formación académica sobre los libros y la lectura a través de los estudios de comunicación no verbal». Didáctica (Lengua y Literatura), Vol. 22, 277-296. 